\title{
PKC $\theta$ utility in diagnosing c-KIT/DOG-1 double negative gastrointestinal stromal tumors
}

\author{
Attila Kövecsi $i^{1,2, *}$, Ioan Jung ${ }^{1, *}$, Zoltan Szentirmay ${ }^{3}$, Tivadar Bara ${ }^{4}$, Tivadar Bara \\ $\mathrm{Jr}^{4}$, Daniel Popa ${ }^{4}$ and Simona Gurzu ${ }^{1,2,5}$ \\ ${ }^{1}$ Department of Pathology, University of Medicine and Pharmacy, Tirgu Mures, Romania \\ 2 Department of Pathology, Clinical County Emergency Hospital, Tirgu Mures, Romania \\ ${ }^{3}$ Department of Molecular Pathology, National Institute of Onology, Budapest, Hungary \\ 4 Department of Surgery, University of Medicine and Pharmacy, Tirgu Mures, Romania \\ ${ }^{5}$ Department of Pathology, CCAMF-Research Center, Tirgu Mures, Romania \\ * These authors have equal contribution to the paper \\ Correspondence to: Simona Gurzu, email: simonagurzu@yahoo.com \\ Keywords: c-theta, protein kinase, GIST, diagnosis, CD1 17, Pathology Section \\ Received: April 04, $2017 \quad$ Accepted: June 04, 2017 \\ Published: July 08, 2017 \\ Copyright: Kövecsi et al. This is an open-access article distributed under the terms of the Creative Commons Attribution License 3.0 (CC BY \\ 3.0), which permits unrestricted use, distribution, and reproduction in any medium, provided the original author and source are credited.
}

\section{ABSTRACT}

Background: The aim of this study was to evaluate the diagnosis value of an immunohistochemical (IHC) panel of three antibodies for the diagnosis of gastrointestinal stromal tumors (GISTs).

Material and methods: In 80 consecutive GISTs without lymph node metastases, the IHC examinations were performed using the antibodies CD117 (C-KIT), DOG-1 and c-theta (PKC $\theta$ ) protein. The diagnostic value of PKC $\theta$ in C-KIT/DOG-1 negative GISTs has been explored in fewer than 10 Medline-indexed papers.

Results: The C-KIT, PKC $\theta$ and DOG-1 positivity was noted in $92.50 \%(n=74)$, $90 \%(n=72)$ and $76.25 \%(n=61)$ of the cases, respectively. All of the C-KIT negative cases $(n=6)$ were also DOG-1 negative but displayed PKC $\theta$ positivity. All of the DOG-1 positive cases $(n=61)$ also expressed c-KIT. No correlation between the examined markers and clinicopathological parameters was noted.

Conclusions: The PKC 1 sensitivity. All of the C-KIT/DOG-1 negative GISTs seem to express PKC $\theta$. For a proper diagnosis of GIST, the C-KIT/DOG-1/PKC $\theta$ panel should be used, with possible therapeutic but not prognostic value.

\section{INTRODUCTION}

Gastrointestinal stromal tumor (GIST) is the most common mesenchymal tumor of the gastrointestinal tract, with a 10-15 per million per year global incidence [1]. It is more frequently diagnosed in the fifth to seventh decades with an approximately equal gender distribution. The most frequent location is the stomach (55-60\%), followed by small intestine (30-35\%), colorectal segments (4-6\%) and esophagus $(<1 \%)$; rarely, GISTs may develop in the mesentery or retroperitoneum, when they are classified as extra-gastrointestinal GISTs (E-GIST) [2, 3].

Morphologically, GISTs may display several types of architecture. The most frequent type is the spindle cell architecture (70\%), followed by epithelioid $(20 \%)$ and mixed type $(10 \%)$. In daily practice, the diagnosis of GIST is mainly based on the immunohistochemical (IHC) marker c-KIT (CD117). Due to its possible positivity in other tumors, such as melanomas, adenoid cystic carcinomas, Merkel cell carcinomas, Kaposi sarcomas, liposarcomas or leiomyomas/leiomyosarcomas, additional markers such DOG-1 (discovered on GIST-1) are used in most of the pathology laboratories $[4,5]$. Those tumors that are negative for both of these markers, although they have KIT or PDGFRA mutations, are difficult to diagnose and remain unrecognized, although they could respond to Imatinib [6-10]. For this reason, new proteins are proposed to support the GIST diagnosis. 
One of the relatively new markers described that are displayed by the c-KIT negative GISTs is the protein kinase $\mathrm{C}-\theta$ (PKC $\theta)$, which is also known as c-theta protein. It is a serine-threonine protein kinase involved in T-cell activation and survival, skeletal muscle signal transduction and differentiation, nerve-muscle interaction, neuronal differentiation, cell proliferation, cancer cellstroma interaction, transcription and apoptosis [6-10]. As the exact role of PKC $\theta$ in GIST is unknown, this IHC marker has not yet been approved for the daily diagnosis of GISTs.

The aim of the study was to analyze the diagnostic sensitivity of the c-KIT, DOG- 1 and PKC $\theta$ expression in GIST and to perform a review of the 15 representative papers indexed in the Medline database (published between June 2004 and March 19, 2017) in the field of the supposed diagnostic value of the PKC $\theta$ [6-20]. Only six of these papers took into account the three markers $[7,9,14-$ $16,18]$. The other nine $[6,8,10,11-13,17,19,20]$ were focused on correlation between c-KIT and PKC $\theta$, without taking into account the DOG-1 expression.

\section{RESULTS}

\section{Correlation between the IHC markers and clinicopathological factors}

The median age of the patients ranged between 19 and 80 years $(61.58 \pm 11.84$ years). The other clinicopathological characteristics are shown in Table 1. All the cases had no lymph node metastasis and were negative for desmin. Distant metastases were identified in liver $(n=5)$ and peritoneum $(n=6)$.



Figure 1: Correlation between c-KIT, DOG-1 and PKC $\theta$ expression revealed by Venn-diagram.
The positive rates of c-KIT and DOG-1 in GISTs were $92.50 \%(74 / 80)$ and $76.25 \%(61 / 80)$ respectively. $\mathrm{PKC} \theta$ positive staining was detected in $72 / 80$ (90\%) cases.

The expression of c-KIT and PKC $\theta$ has no significant correlation with clinicopathological parameters including gender, age, tumor size, mitotic rate, tumor location, histological type, risk degree, local invasion or presence of distant metastasis or intratumoral necrosis (Table 2).

Out of all the examined clinicopathological parameters, DOG-1 was only correlated with tumor location. Although the DOG-1 positive cases have predominated, significant positivity was noted for the GIST that involved the small intestine or retroperitoneal area (Table 2).

\section{Correlation between the four examined IHC markers}

The value of the Ki67 index was directly correlated with c-KIT expression without correlation with DOG-1 or PKC $\theta$ (Table 2).

Out of the examined cases, 70\% (56/80) expressed all the three examined markers: c-KIT, DOG- 1 and PKC $\theta$. All of the 61 DOG-1 positive cases and 13 of the 19 DOG1 negative GISTs $(68.42 \%$ ) displayed c-KIT positivity ( $p$ $=0.0001)$.

PKC $\theta$ was expressed in 66 out of the $74 \mathrm{c}-\mathrm{KIT}$ positive GISTs and 56 out of the 61 DOG- 1 positive cases (89.18\% and $91.80 \%$ respectively). All of the six DOG1 negative/ c-KIT negative cases expressed PKC $\theta$. From the 13 DOG-1 negative/c-KIT positive cases, 10 cases $(76.92 \%)$ displayed diffuse PKC $\theta$ positivity. All of the eight PKC $\theta$ negative GISTs were positive for c-KIT; five out of eight cases also expressed DOG-1 (Figure 1).

\section{DISCUSSION}

In patients with GIST, the previously published papers showed a c-KIT positivity rate of $80-100 \%$, in line with the present study $[8,19,22,23]$. The c-KIT negative cases were reported to be more frequently located on the stomach (96\% of all negative GISTs) and displaying epithelioid or spindle cell-type architecture [7, 19]. In the present study, regardless of the tumor's location, the two epithelioid-type GISTs were c-KIT negative.

DOG-1 is a transmembrane protein located on the $11 \mathrm{q} 13$ chromosome that was reported to be IHC-expressed in $57-96 \%$ of GISTs $[9,14,23]$. Its expression is directly correlated with c-KIT positivity [14]; all of the DOG-1 positive cases expressed c-KIT in our material but not all of the c-KIT positive GISTs were also positive for DOG-1. Usually, DOG-1 does not mark other tumors, such as leiomyomas/leiomyosarcomas, melanomas, schwannomas, malignant peripheral nerve sheath tumors, 
Table 1: Clinicopathological characteristics of patients

\begin{tabular}{|c|c|}
\hline Variable & $n=80$ \\
\hline Age (years) & $61.58 \pm 11.84$ (range $19-80$ years) \\
\hline Gender: Male/Female & $35 / 45(1: 1.28)$ \\
\hline \multicolumn{2}{|c|}{ Tumor size (Median: $6.47 \pm 4.67 \mathrm{~cm}$, range 0.4 to $21 \mathrm{~cm}$ ) } \\
\hline$\geq 5 \mathrm{~cm}$ & 45 \\
\hline$<5 \mathrm{~cm}$ & 35 \\
\hline \multicolumn{2}{|c|}{ Mitoses (50HPF) (Median: $8.43 \pm 14.02$, range 0 to 89 ) } \\
\hline$\geq 5$ & 29 \\
\hline$<5$ & 51 \\
\hline \multicolumn{2}{|l|}{ Tumor location } \\
\hline Stomach & 35 \\
\hline Small intestine & 25 \\
\hline Colorectum & 6 \\
\hline E-GIST & 14 \\
\hline \multicolumn{2}{|l|}{ Histological pattern } \\
\hline Spindle cell & 64 \\
\hline Epithelioid cell & 2 \\
\hline Mixed & 14 \\
\hline \multicolumn{2}{|l|}{ Risk group } \\
\hline Very low & 10 \\
\hline Low & 21 \\
\hline Intermediate & 16 \\
\hline High & 33 \\
\hline \multicolumn{2}{|l|}{ Ki67 index } \\
\hline Low $(\leq 5 \%)$ & 60 \\
\hline High $(>5 \%)$ & 20 \\
\hline \multicolumn{2}{|l|}{ Local invasion } \\
\hline present & 14 \\
\hline absent & 66 \\
\hline \multicolumn{2}{|l|}{ Distant metastases } \\
\hline present & 11 \\
\hline absent & 69 \\
\hline \multicolumn{2}{|l|}{ Necrosis } \\
\hline present & 32 \\
\hline absent & 48 \\
\hline
\end{tabular}

inflammatory fibroid polyps, small cell carcinomas, Merkel cell carcinomas or seminomas [7, 15, 24]. Uncommonly, DOG-1 sporadic positivity was reported for renal tubes, eccrine glands and hair follicles. Some tumors such as dermatofibrosarcomas, uterine-type retroperitoneal leiomyomas (8\%), peritoneal leiomyomatoses $(23 \%)$, leiomyosarcomas and other soft tissue tumors with histiocytic or lipomatous differentiation, carcinomas of the esophagus (60\%), stomach (26\%) and colorectal segments (5\%), basal cell carcinomas (6\%), squamous cell carcinomas (21\%), hepatocellular carcinomas, adenoid cystic carcinomas, synovial sarcomas (16\%) and desmoplastic melanomas (1\%) also displayed DOG-1 positivity $[9,15,23-26]$. 
Table 2: Correlation of the immunohistochemical expression of c-KIT, DOG-1 and PKC $\theta$ with the clinicopathological parameters $(\mathbf{N A}=$ non-available $)$

\begin{tabular}{|c|c|c|c|c|c|c|c|c|c|c|c|c|c|}
\hline & \multirow{2}{*}{$n$} & \multicolumn{4}{|c|}{ c-KIT } & \multicolumn{4}{|c|}{ DOG-1 } & \multicolumn{4}{|c|}{ PKC-theta } \\
\hline & & - & + & OR (CI:95\%) & $p$ & - & + & OR (CI:95\%) & $p$ & - & + & OR (CI:95\%) & $p$ \\
\hline \multicolumn{14}{|l|}{ Gender } \\
\hline Male & 35 & 5 & 30 & \multirow{2}{*}{$7.33(0.81-66.00)$} & \multirow{2}{*}{0.08} & 9 & 26 & \multirow{2}{*}{$1.21(0.43-3.40)$} & \multirow{2}{*}{0.79} & 1 & 34 & \multirow{2}{*}{$0.15(0.01-1.36)$} & \multirow{2}{*}{0.07} \\
\hline Female & 45 & 1 & 44 & & & 10 & 35 & & & 7 & 38 & & \\
\hline \multicolumn{14}{|l|}{ Age (years) } \\
\hline$\leq 45$ & 8 & 0 & 8 & \multirow{2}{*}{$0.60(0.03-11.67)$} & \multirow{2}{*}{0.98} & 2 & 6 & \multirow{2}{*}{$1.07(0.19-5.84)$} & \multirow{2}{*}{0.98} & 0 & 8 & \multirow{2}{*}{$0.44(0.02-8.44)$} & \multirow{2}{*}{1} \\
\hline$>45$ & 72 & 6 & 66 & & & 17 & 55 & & & 8 & 64 & & \\
\hline \multicolumn{14}{|l|}{ Tumor size } \\
\hline$\geq 5 \mathrm{~cm}$ & 45 & 4 & 41 & \multirow{2}{*}{$1.61(0.27-9.34)$} & \multirow{2}{*}{0.69} & 11 & 34 & \multirow{2}{*}{$1.09(0.38-3.09)$} & & 5 & 40 & & \\
\hline$<5 \mathrm{~cm}$ & 35 & 2 & 33 & & & 8 & 27 & & 0.95 & 3 & 32 & $1.33(0.29-6.00)$ & 1 \\
\hline Mitotic rate (50HPF & & & & & & & & & & & & & \\
\hline $\operatorname{High}(\geq 5)$ & 29 & 2 & 27 & & & 5 & 24 & & & 2 & 27 & & \\
\hline Low $(<5)$ & 51 & 4 & 47 & $0.8 /(0.14-5.07)$ & 0.95 & 14 & 37 & $0.55(0.1 /-1.12)$ & 0.41 & 6 & 45 & $0.55(0.10-2.95)$ & 0.49 \\
\hline Tumor location & & & & & & & & & & & & & \\
\hline Stomach & 35 & 2 & 33 & & & 10 & 25 & & & 3 & 32 & & \\
\hline Small intestine & 25 & 1 & 24 & & & 3 & 22 & & 0.02 & 3 & 22 & & \\
\hline Colorectum & 6 & 2 & 4 & & & 4 & 2 & & & 1 & 5 & & \\
\hline E-GIST & 14 & 1 & 13 & & & 2 & 12 & & & 1 & 13 & & \\
\hline Histological pattern & & & & & & & & & & & & & \\
\hline Spindle cell type & 64 & 4 & 60 & & & 15 & 49 & & & 6 & 58 & & \\
\hline Epithelioid cell type & 2 & 0 & 2 & NA & 0.53 & 0 & 2 & NA & 0.66 & 0 & 2 & NA & 0.82 \\
\hline Mixed type & 14 & 2 & 12 & & & 4 & 10 & & & 2 & 12 & & \\
\hline Risk group & & & & & & & & & & & & & \\
\hline Very low & 10 & 1 & 9 & & & 3 & 7 & & & 3 & 7 & & \\
\hline Low & 21 & 1 & 20 & & & 5 & 16 & & & 1 & 20 & & \\
\hline Intermediate & 16 & 2 & 14 & NA & 0.80 & 4 & 12 & NA & 0.95 & 1 & 15 & NA & 0.14 \\
\hline High & 33 & 2 & 31 & & & 7 & 26 & & & 3 & 30 & & \\
\hline Ki67 index & & & & & & & & & & & & & \\
\hline Low & 60 & 2 & 58 & & & 13 & 47 & & & 7 & 53 & & \\
\hline High & 20 & 4 & 16 & $0.13(0.02-0.82)$ & 0.03 & 6 & 14 & $0.64(0.20-2.01)$ & 0.54 & 1 & 19 & $2.50(0.28-21.75)$ & 0.40 \\
\hline Local invasion & & & & & & & & & & & & & \\
\hline positive & 14 & 2 & 12 & $258(042-1574)$ & 028 & 2 & 12 & $0.48(0.09-237)$ & 0.49 & 1 & 13 & $0.64(0.07-7,53)$ & 069 \\
\hline negative & 66 & 4 & 62 & & & 17 & 49 & & & 7 & 59 & & \\
\hline Distant metastasis & & & & & & & & & & & & & \\
\hline present & 11 & 0 & 11 & & & 2 & 9 & & & 1 & 10 & & \\
\hline absent & 69 & 6 & 63 & $0.42(0.02-8.06)$ & 0.58 & 17 & 52 & $0.6 /(0.13-3.45)$ & 0.64 & 7 & 62 & $0.88(0.09-7.98)$ & 0.91 \\
\hline Necrosis & & & & & & & & & & & & & \\
\hline present & 32 & 3 & 29 & & & 8 & 24 & & & 2 & 30 & & \\
\hline absent & 48 & 3 & 45 & $1.53(0.29-0.22)$ & 0.07 & 11 & 37 & $1.12(0.29-5.19)$ & 0.93 & 6 & 42 & $0.40(0.00-2.4 /)$ & (0.3) \\
\hline
\end{tabular}


PKC $\theta$ was previously reported to be expressed in the interstitial cells of the Cajal lineage, Auerbach's plexus, T-cells, mast cells, endothelial cells, lymphoid organs, nervous system, skeletal muscle, and $72-100 \%$ of GISTs, without positivity for other c-KIT negative soft tissue tumors, desmoid tumors or carcinomas [6, $8-10,14,20]$. It is important to mention that the c-KIT positive non-GIST tumors, such as small or large cell carcinomas, renal chromophobe cell carcinomas, thymic carcinomas or seminomas, did not display PKC $\theta$ positivity $[6,10]$. However, the referenced studies $[6,10,20]$ only included 26-48 GISTs and 1-10 cases from the nonsarcomatous tumors. Weak PKC $\theta$ expression was reported by other researchers in $25-33 \%$ of leiomyomas, $6-28 \%$ of leiomyosarcomas, $33 \%$ of malignant peripheral nerve sheath tumors/Ewing sarcomas, $10-57 \%$ of gastrointestinal schwannomas (especially in Verocay bodies), $15 \%$ of desmoid tumors, more than one-third of melanomas and $10 \%$ of adenoid cystic carcinomas $[6,7,9,15,19,20]$.

In our study, all of the three IHC markers were expressed in $70 \%$ of GISTs and the sensitivity of the polyclonal c-KIT and PKC $\theta$ was nearly identical: $92.50 \%$ versus $90 \%$, similar to some of the literature data [9]. The sensitivity of both markers was superior to the K9 clone of DOG-1 (76.25\%). Other authors proved a similar sensitivity of c-KIT and DOG-1 but admitted a slightly greater c-KIT positivity for the tumors localized on the colorectal segments $[23,27]$ and a relatively higher sensitivity of the clone SP31 versus the commercial K9 clone of DOG-1 that was used in the present study $(95 \%$ versus $90-94 \%$ ) $[9,15]$. The heterogeneity of the studies, the small number of examined cases and the paucity of the used clones induce discrepant results, with even a higher DOG-1 or PKC $\theta$ sensitivity, compared with c-KIT, being proved $[6,10,15,27]$. The differences can also be explained by the predominance of the DOG-1 positive cases in the tumors of the small intestine and E-GISTs, proved by the present material. In other studies, the gastrointestinal GISTs predominated [10]. Moreover, none of our cases showed lymph node metastases.

The PKC $\theta$ diagnostic value seems to be important for the c-KIT negative cases [7, 9]. A 70-100\% PKC $\theta$ positivity was previously reported in c-KIT negative GISTs regardless of KIT or PDGFRA status [8, 19, 20]. PKC $\theta$ also marked the PDGFRA mutant GISTs (for exons 12 or 18) that are negative for c-KIT and even the cases with myxoid stroma $[6,19]$. Overexpression of the $P K C \theta$ gene and PKC $\theta$ expression at the RNA level were also displayed in GIST samples but not in other c-KIT positive non-GIST soft tissue sarcomas or other tumors $[10,20]$.

Although a correlation between c-KIT and DOG-1 was proved by most of the studies, discrepant results were founded for c-KIT negative cases. The c-KIT negative GISTs are $36-100 \%$ DOG-1 positive [15], express either DOG- 1 or PKC $\theta$ or show double positivity for DOG-1 and PKC $\theta[7,9]$ but can also be negative for both DOG-1 and

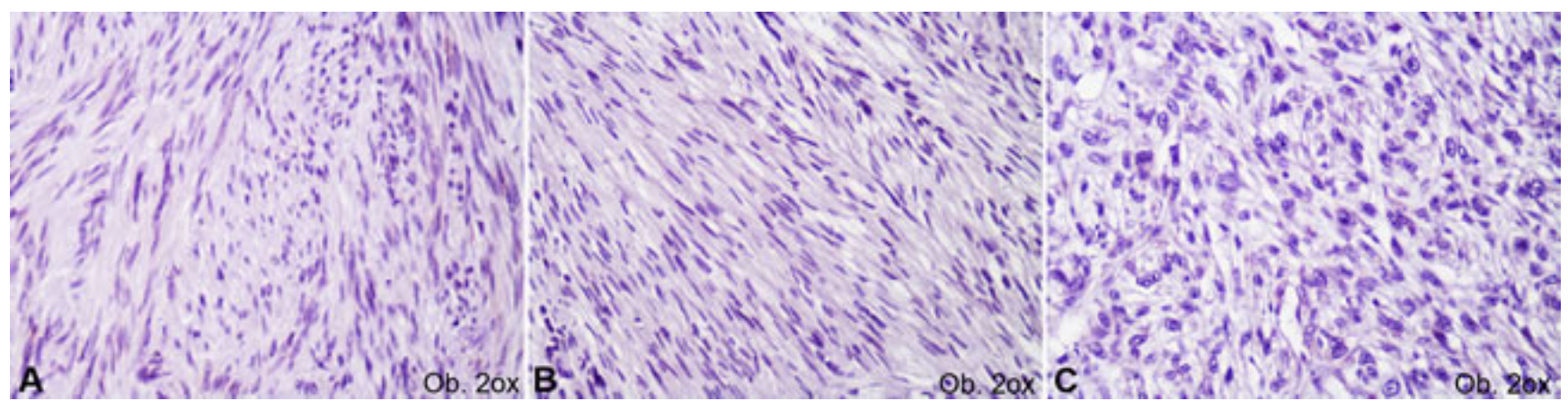

Figure 2: Negative immunoexpression of c-KIT (A), DOG-1 (B) and PKC $\theta(\mathbf{C})$ in gastrointestinal stromal tumors.
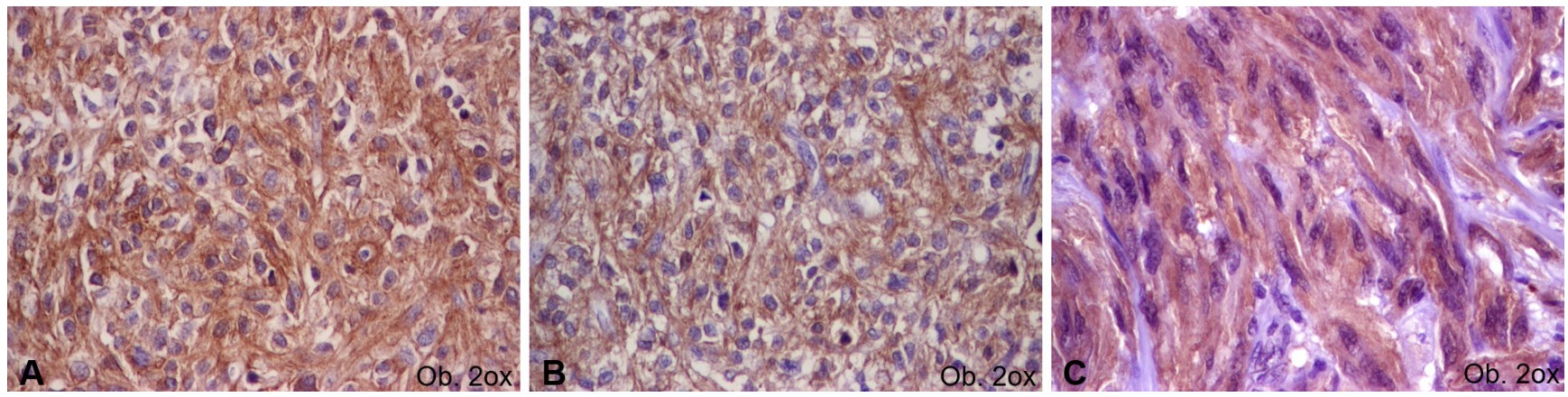

Figure 3: Positive immunoexpression of c-KIT (A), DOG-1 (B) and PKC $\theta(\mathbf{C})$ in gastrointestinal stromal tumors. 
PKC $\theta$ (2/5 cases) [9]. The uncommon DOG- 1 negativity was proved in only $3-4 \%$ of c-KIT negative GISTs; they are usually wild type KIT/PDGFRA mutant cases [9]. To our knowledge, the diagnostic value of PKC $\theta$ in double c-KIT/DOG-1 negative GISTs was shown in only three papers: 2/26 [7], 1/5 [9] and 1/1 c-KIT negative GISTs [16]. In all of these cases, PKC $\theta$ positivity was proved, as in this material, which comprised the largest reported case series of c-KIT/DOG-1 negative GISTs displaying PKC $\theta$ positivity (6/6 c-KIT negative GISTs selected from 80 GISTs). In one of the studies, the molecular examinations performed in c-KIT negative GISTs showed mutations in: $K I T$ exon 11 for DOG-1 negative/PKC $\theta$ negative GISTs (two cases), PDGFRA exon 18 for DOG-1 negative/ PKC $\theta$ positive (one case) or DOG-1 positive/PKC $\theta$ positive GISTs (one case), and PDGFRA exon 12 for DOG-1 positive/PKC $\theta$ positive GISTs (one case) [9]. The PKC $\theta$ negative GISTs showed $c$-KIT mutations in exon 11 regardless of the other IHC markers [19].

Similar $P K C \theta$ gene expression levels were proved when detected with a goat polyclonal or a mouse monoclonal antibody [20]. It may be mandatory to prove the PKC $\theta$ positivity to confirm the diagnosis of GIST, but its negativity is uninformative [20] because all of the PKC $\theta$ negative GISTs display c-KIT and CD34 positivity [6], with/without DOG-1 expression [9], similar to our data.

In the present study, no one of the three examined markers proved to be an indicator of prognosis. They proved to be valuable as diagnostic tools only. The main limitations of this study are the small number of cases and absence of cases with lymph node metastases.

As the possible role of PKC $\theta$ in protecting T-cells from apoptosis and promoting activation of the immune cells' inflammation, as well as in promoting multidrug resistance (MDR), was previously proved [10, 28, 29], we conclude that PKC $\theta$ might be a novel therapeutic target for the immune therapy of GISTs or a potential indicator of resistance to Imatinib. In c-KIT/DOG-1 negative GISTs, the PKC $\theta$ expression should be checked for a complex differential diagnosis.

\section{MATERIALS AND METHODS}

\section{Tissue samples}

The present retrospective study included 80 formalin-fixed and paraffin-embedded tissue samples of primary GISTs. The surgically removed GIST specimens from consecutive cases were retrospectively collected from the Department of Pathology of the Clinical County Emergency Hospital of Tirgu-Mures, Romania, from 2003 to 2015. No neoadjuvant chemotherapy was given prior to resection. The approval of the Ethical Committee of the
University of Medicine and Pharmacy of Tirgu-Mures, Romania, was obtained for retrospective evaluation of the cases.

The morphological diagnosis of GIST was confirmed by two pathologists, the histological pattern was identified and the mitotic index was calculated. The main prognostic factors, such as size, mitotic index and anatomical location, were analyzed based on the NIH's modified consensus classification [21].

\section{Immunohistochemical analysis}

For IHC analyses, tissue microarray (TMA) blocks were performed, containing three representative areas of each GIST tissue (3 $\mathrm{mm}$ diameter core). The IHC stains were performed using the antibodies c-KIT (rabbit polyclonal, DAKO Glostrup, Denmark, dilution 1:500), DOG-1 (mouse monoclonal, clone K9, Novocastra, Newcastle, UK, dilution 1:50), Ki67 (MIB1 clone, DAKO, dilution 1:500), and PKC $\theta$ (polyclonal, ABCAM, dilution 1:200) according to the instructions of the manufacturer. The developing was performed with DAB (diaminobenzidine) solution (Novocastra). For the negative controls, incubation was conducted with the omission of specific antibodies [30].

The cut-off value used was $5 \%$ for Ki67. The c-KIT, DOG-1 and PKC $\theta$ marked the cell cytoplasm with/ without membrane positivity. In line with the previous studies, cases with positivity in a few single cells were considered negative (Figure 2); positive cases (Figure 3) showed focal or diffuse unequivocal positivity in several cell clusters or more than $10 \%$ of the tumor cells $[7,10]$. The IHC assessment was performed independently by two pathologists.

\section{Statistical analysis}

Statistical analysis was performed using the GraphPad InStat 3 software and two-sided tests. A $p$-value $<0.05$ with $95 \%$ confidence interval was considered statistically significant.

\section{ACKNOWLEDGMENTS}

The English Proofread Editing Service polished the English-language manuscript.

\section{FUNDING}

This work was partially supported by the University of Medicine and Pharmacy of Tirgu-Mures, Romania, in the joint project with Studium Prospero Foundation and Hungarian Science Academy, research projects frame $136 / 2017$. 


\section{CONFLICT OF INTERESTS}

No conflict of interests are declared.

\section{REFERENCES}

1. Rubin BP, Heinrich MC, Corless CL. Gastrointestinal stromal tumour. Lancet. 2007; 369:1731-1741.

2. Soreide K, Sandvik OM, Soreide JA, Giljaca V, Jureckova A, Bulusu VR. Global epidemiology of gastrointestinal stromal tumours (GIST): a systematic review of populationbased cohort studies. Cancer Epidemiol. 2016; 40:39-46.

3. Klieser E, Pichelstorfer M, Weyland D, Kemmerling R, Swierczynski S, Dinnewitzer A, Jager T, Kiesslich T, Neureiter D, Illig R. Back to the start: evaluation of prognostic markers in gastrointestinal stromal tumors. Mol Clin Oncol. 2016; 4:763-773.

4. Fletcher CD, Berman JJ, Corless C, Gorstein F, Lasota J, Longley BJ, Miettinen M, O’Leary TJ, Remotti H, Rubin BP, Shmookler B, Sobin LH, Weiss SW. Diagnosis of gastrointestinal stromal tumors: a consensus approach. Hum Pathol. 2002; 33:459 465.

5. Nishida T, Blay JY, Hirota S, Kitagawa Y, Kang YK. The standard diagnosis, treatment, and follow-up of gastrointestinal stromal tumors based on guidelines. Gastric Cancer. 2016; 19:3-14.

6. Motegi A, Sakurai S, Nakayama H, Sano T, Oyama T, Nakajima T. PKC theta, a novel immunohistochemical marker for gastrointestinal stromal tumors (GIST), especially useful for identifying KIT-negative tumors. Pathol Int. 2005; 55:106-112.

7. Kang GH, Srivastava A, Kim YE, Park HJ, Park CK, Sohn TS, Kim S, Kang DY, Kim KM. DOG- 1 and PKC- $\theta$ are useful in the diagnosis of KIT-negative gastrointestinal stromal tumors. Mod Pathol. 2011; 24:866-875.

8. Lee HE, Kim MA, Lee HS, Lee BL, Kim WH. Characteristics of KIT-negative gastrointestinal stromal tumors and diagnostic utility of protein kinase $\mathrm{C}$ theta immunostaining. J Clin Pathol. 2008; 61:722-729.

9. Rios-Moreno MJ, Jaramillo S, Pereira Gallardo S, Vallejo A, Mora M, Garcia-Escudero A, Amerigo J, GonzalezCampora R. Gastrointestinal stromal tumors (GISTs): CD117, DOG-1 and PKC $\theta$ expression. Is there any advantage in using several markers? Pathol Res Pract. 2012; 208:74-81.

10. Blay P, Astudillo A, Buesa JM, Campo E, Abad M, GarciaGarcia J, Miquel R, Marco V, Sierra M, Losa R, Lacave A, Brana A, Balbin M, et al. Protein kinase $\mathrm{C}$ theta is highly expressed in gastrointestinal stromal tumors but not in other mesenchymal neoplasias. Clin Cancer Res. 2004; 10:40894095 .

11. Zhu MJ, Ou WB, Fletcher CD, Cohen PS, Demetri GD, Fletcher JA. KIT oncoprotein interactions in gastrointestinal stromal tumors: therapeutic relevance. Oncogene. 2007;
26:6386-6395.

12. Ou WB, Zhu MJ, Demetri GD, Fletcher CD, Fletcher JA. Protein kinase C-theta regulates KIT expression and proliferation in gastrointestinal stromal tumors. Oncogene. $2008 ; 27: 5624-5634$

13. Zhang L, Smyrk TC, Young WF Jr, Stratakis CA, Carney JA. Gastric stromal tumors in Carney triad are different clinically, pathologically, and behaviorally from sporadic gastric gastrointestinal stromal tumors: findings in 104 cases. Am J Surg Pathol. 2010; 34:53-64.

14. Kang YN, Jung HR, Hwang I. Clinicopathological and immunohistochemical features of gastointestinal stromal tumors. Cancer Res Treat. 2010; 42:135-143.

15. Fatima N, Cohen C, Siddiqui MT. DOG-1 utility in diagnosing gastrointestinal stromal tumors on fine-needle aspiration. Cancer Cytopathol. 2011; 119:202-208.

16. Kim KH, Nelson SD, Kim DH, Choi KU, Kim SJ, Min KW, Jang KS, Paik SS, Oh YH, Chae SW, Sohn JH, Kim HJ, Cho YK, et al. Diagnostic relevance of overexpressions of PKC- $\theta$ and DOG- 1 and KIT/PDGFRA gene mutations in extragastrointestinal stromal tumors: a Korean six-centers study of 28 cases. Anticancer Res. 2012; 32:923-937.

17. Valadao M, Braggio D, Santos AF, Pimenta-Inada HK, Linhares E, Gonçalves R, Romano S, Vilhena B, Small I, Cubero D, Cruz F, Oliveira AT, Martinho O, et al. Involvement of signalling molecules in the prediction of response to imatinib treatment in metastatic GIST patients. J Surg Res. 2012; 178:288-293.

18. Wang C, Jin MS, Zou YB, Gao JN, Li XB, Peng F, Wang HY, Wu ZD, Wang YP, Duan XM. Diagnostic significance of DOG-1 and PKC- $\theta$ expression and c-Kit/PDGFRA mutations in gastrointestinal stromal tumours. Scand J Gastroenterol. 2013; 48:1055-1065.

19. Kim KM, Kang DW, Moon WS, Park JB, Park CK, Sohn JH, Jeong JS, Cho MY, Jin SY, Choi JS, Kang DY. PKCtheta expression in gastrointestinal stromal tumor. Mod Pathol. 2006; 19:1480-1486.

20. Duensing A, Joseph NE, Medeiros F, Smith F, Hornick JL, Heinrich MC, Corless CL, Demetri GD, Fletcher CD, Fletcher JA. Protein Kinase C theta (PKCtheta) expression and constitutive activation in gastrointestinal stromal tumors (GISTs). Cancer Res. 2004; 64:5127-5131.

21. Joensuu H. Risk stratification of patients diagnosed with gastrointestinal stromal tumor. Hum Pathol. 2008; 39:14111419.

22. Xu C, Han H, Wang J, Zhang B, Shao Y, Zhang L, Wang H, Wang H, Wu Y, Li X, Li R, Tian Y. Diagnosis value of CD117, PDGFRA alone or in combination DOG-1, as biomarkers for gastrointestinal stromal tumors. Ann Transl Med. 2015; 3:308.

23. Miettinen M, Wang ZF, Lasota J. DOG-1 antibody in the differential diagnosis of gastrointestinal stromal tumors: a study of 1840 cases. Am J Surg Pathol. 2009; 33:14011408 
24. Turdean SG, Gurzu S, Jung I, Neagoe RM, Sala D. Unexpected maspin immunoreactivity in Merkel cell carcinoma. Diagn Pathol. 2015; 10:206.

25. Jung I, Gurzu S, Turdean S, Ciortea D, Sahlean DI, Golea M, Bara T. Relationship of endothelial area with VEGF-A, COX-2, maspin, c-KIT, and DOG-1 immunoreactivity in liposarcomas versus non-lipomatous soft tissue tumors. Int J Clin Exp Pathol. 2015; 8:1776-1782.

26. Ciortea CD, Jung I, Gurzu S, Kovecsi A, Turdean SG, Bara T. Correlation of angiogenesis with other immunohistochemical markers in cutaneous basal and squamous cell carcinomas. Rom J Morphol Embryol. 2015; 56:665-670.

27. Liegl B, Hornick JL, Corless CL, Fletcher CD. Monoclonal antibody DOG-1-1 shows higher sensitivity than KIT in the diagnosis of gastrointestinal stromal tumors, including unusual subtypes. Am J Surg Pathol. 2009; 33:437-446.
28. Gill PK, Gescher A, Gant TW. Regulation of MDR1 promoter activity in human breast carcinoma cells by protein kinase $\mathrm{C}$ isozymes alpha and theta. Eur J Biochem. 2001; 268:4151-4157.

29. Marrocco V, Fiore P, Benedetti A, Pisu S, Rizzuto E, Musaro A, Madaro L, Lozanoska-Ochser B, Bouche M. Pharmacological inhibition of PKC $\theta$ counteracts muscle disease in a mouse model of duchenne muscular dystrophy. EBioMedicine. 2017; 16:150-161.

30. Shi Z, Stack MS. An update on immunohistochemistry in translational cancer research. Cancer Transl Med. 2015; $1: 115-122$ 